\title{
Uncontrollable uterine atony after replacement of uterine inversion managed by hysterectomy: a case report
}

\author{
Daisuke Katsura ${ }^{1 *} \mathbb{D}$, Suzuko Moritani ${ }^{2}$, Shunichiro Tsuji ${ }^{1}$, Kounosuke Suzuki $^{1}$, Kazutaka Yamada ${ }^{1}$, Mizuki Ohashi ${ }^{1}$,
} Fuminori Kimura ${ }^{1}$ and Takashi Murakami ${ }^{1}$

\begin{abstract}
Background: Uterine inversion may cause massive hemorrhage, resulting in maternal deterioration and death. Replacement of the inverted uterus must be performed as soon as possible. As time passes, the inverted uterus becomes atonic and necrotic, and a surgical approach may be required.

Case presentation: A 27-year-old Japanese woman was admitted to our hospital 4 hours postpartum with increased hemorrhage after the replacement of an inverted uterus. Recurrent inversion was diagnosed, and though the atonic uterus was replaced again by the Johnson maneuver, hemorrhage persisted. Balloon tamponade was not successful in stopping the hemorrhage, and uterine artery embolization was performed. Bleeding resumed the next day on removal of the balloon, and hysterectomy was performed. Massive hemorrhage, coagulopathy, and uterine necrosis caused uterine atony, and the reperfused blood flow on replacement of the ischemic uterus increased hemorrhage.

Conclusions: Cases of uterine inversion with coagulopathy lasting for more than 4 hours may require a surgical intervention, and uterine replacement may have to be delayed until the maternal hemodynamic condition is stabilized. Uterine replacement under laparotomy may be also be considered due to the risk of increased hemorrhage.
\end{abstract}

Keywords: uterine inversion, replacement, atony of uterus, reperfused blood flow, ischemic uterus, case report

\section{Background}

Although uterine inversion is a rare obstetric emergency and occurs in only 1 in 20,000 vaginal births, it causes acute maternal blood loss and can lead to maternal death [1]. Therefore, prompt management with fluid resuscitation and control of hemorrhage is important. In particular, the inverted uterus must be replaced as soon as possible because the success rate decreases with the involution of the cervix, which induces a rigid ring that

\footnotetext{
* Correspondence: katsuo14@belle.shiga-med.ac.jp

${ }^{1}$ Department of Obstetrics and Gynecology, Shiga University of Medical Science Hospital, Setatsukinowa-cho, Otsu, Shiga 520-2192, Japan Full list of author information is available at the end of the article
}

makes restoration of the normal uterus position difficult $[2,3]$. As time passes, the uterus becomes atonic and necrotic, and a surgical approach may be required [2-4]. However, the time from inversion to the occurrence of uterine atony and necrosis is uncertain.

We encountered a case of a patient with increased hemorrhage and coagulopathy after the replacement of a uterine inversion that had persisted for 4 hours.

\section{Case presentation}

A 27-year-old Japanese woman with unremarkable medical and family history was impregnated through in vitro fertilization. At 40 weeks of gestation, she was admitted

C The Author(s). 2020 Open Access This article is licensed under a Creative Commons Attribution 4.0 International License, which permits use, sharing, adaptation, distribution and reproduction in any medium or format, as long as you give appropriate credit to the original author(s) and the source, provide a link to the Creative Commons licence, and indicate if changes were made. The images or other third party material in this article are included in the article's Creative Commons licence, unless indicated otherwise in a credit line to the material. If material is not included in the article's Creative Commons licence and your intended use is not permitted by statutory regulation or exceeds the permitted use, you will need to obtain permission directly from the copyright holder. To view a copy of this licence, visit http://creativecommons.org/licenses/by/4.0/ The Creative Commons Public Domain Dedication waiver (http://creativecommons.org/publicdomain/zero/1.0/) applies to the data made available in this article, unless otherwise stated in a credit line to the data. 
to an obstetric clinic for premature rupture of the membranes and vaginal delivery by induced labor. After delivery, a large mass emerged through the vaginal passage with the placenta, and the placenta was removed. Uterine inversion was diagnosed, and manual repositioning of the uterus was performed with oxytocin administration. However, because hemorrhage persisted, she was referred to our hospital 4 hours postpartum.

On admission, she had lost over $4000 \mathrm{~mL}$ of blood, was unconscious, and her blood pressure could not be measured. Laboratory tests revealed hemoglobin, platelet, and fibrinogen levels of $3.4 \mathrm{~g} / \mathrm{dl}, 18.2 \times 10^{4} / \mu \mathrm{l}$, and $131 \mathrm{mg} / \mathrm{dl}$, respectively. We started rapid blood transfusion, intubated her, administered oxygen, and diagnosed uterine inversion by vaginal examination and abdominal ultrasonography (Fig. 1). Although we successfully replaced the inverted uterus using the Johnson maneuver followed by internal bimanual compression, the uterus was markedly atonic and the hemorrhage increased. Balloon tamponade was performed to stop the hemorrhage and reduce the risk of recurrence. However, hemorrhage persisted at a rate of $350 \mathrm{~mL} / \mathrm{min}$. She went into cardiopulmonary arrest and was resuscitated after 11 minutes. She presented with a pulse rate of 140 beats per minute (bpm) and a blood pressure of 70/40 mmHg. Laboratory tests revealed hemoglobin, platelet, and fibrinogen levels of $5.3 \mathrm{~g} / \mathrm{dl}, 3.9 \times 10^{4} / \mu \mathrm{l}$, and $116 \mathrm{mg} / \mathrm{dl}$, respectively. To stop the hemorrhage immediately, uterine artery embolization was performed instead of hysterectomy because of disseminated intravascular coagulation, and the hemorrhage stopped. She presented with a pulse rate of $100 \mathrm{bpm}$ and a blood pressure of 120/70 mmHg. Laboratory tests revealed hemoglobin, platelet, and fibrinogen levels of $9.5 \mathrm{~g} / \mathrm{dl}, 6.8 \times 10^{4} / \mu \mathrm{l}$, and $147 \mathrm{mg} / \mathrm{dl}$, respectively. She required transfusion of 38 units of fresh frozen

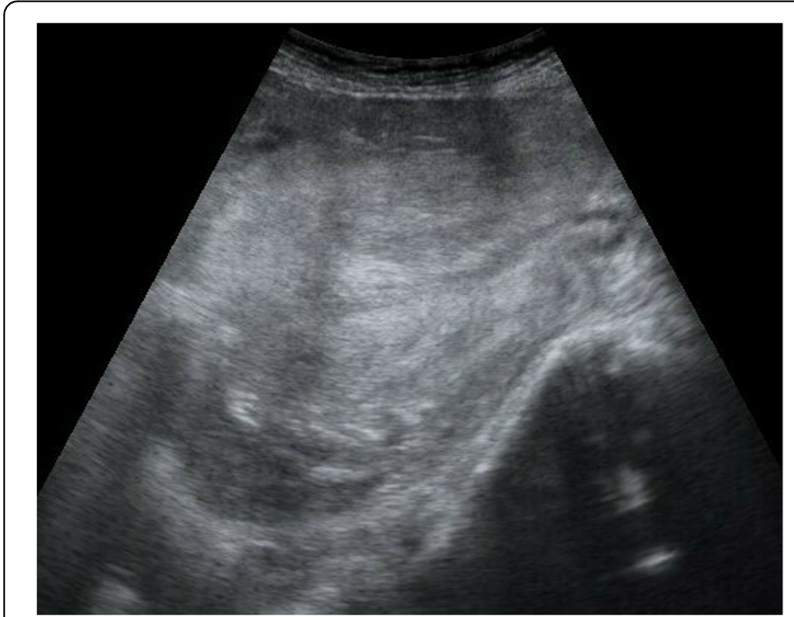

Fig. 1 Abdominal ultrasonography findings. The uterine fundus passes through the cervical ring (sagittal view: right side - patient's head, left side - patient's leg) plasma and 22 units of packed red blood cell concentrate. When the balloon was removed one day later, bleeding increased again, and she experienced a hemorrhage of $500 \mathrm{ml}$ in 2 hours. Therefore, a hysterectomy was performed, and her condition stabilized. She presented with a pulse rate of $80 \mathrm{bpm}$ and a blood pressure of $140 / 70 \mathrm{mmHg}$. Laboratory tests revealed hemoglobin, platelet, and fibrinogen levels of $8.6 \mathrm{~g} / \mathrm{dl}$, $8.6 \times 10^{4} / \mu \mathrm{l}$, and $297 \mathrm{mg} / \mathrm{dl}$, respectively. Subsequently, computed tomography revealed brain edema and a fogging effect in the cortico-medullary junction, and she was diagnosed with postresuscitation encephalopathy. Her cerebral activity potential could not be confirmed, and communication with her is difficult, although she opens her eyes spontaneously and responds slightly to painful stimulation.

Placental and uterine histopathological examination revealed placenta accreta on part of the uterine fundus (because of no decidua) and necrosis in the fundus and on the surface of the surrounding muscle layer.

\section{Discussion}

When uterine inversion occurs, we must replace the inverted uterus immediately before a uterine contraction ring forms [2, 3]. Close follow-up is required because uterine inversion can recur $[4,5]$. In addition, surgery may be required if the uterus becomes atonic and necrotic [2-4]. In our case, the persistent hemorrhage suggested recurrent uterine inversion after manual repositioning of the uterus. Although there was a 4-hour delay from the recurrent uterine inversion, we easily replaced the uterus. However, the uterus did not contract at all, and hemorrhage increased. We speculated that the replacement was easy because massive hemorrhage and concomitant coagulopathy might have caused remarkable atony of the uterus [6, 7]. However, hemorrhage increased on replacement of the uterus because the blood flow was reperfused into the ischemic uterus. Therefore, in cases of uterine inversion with coagulopathy that persists for a significant period, uterine replacement may have to be delayed until after fluid resuscitation and blood transfusion can stabilize the maternal hemodynamic condition. Furthermore, uterine replacement under laparotomy may be considered because hemorrhage may increase after uterine replacement; thus, we can promptly perform a uterine compression suture, stepwise uterine devascularization, or/and hysterectomy.

In addition, uterine necrosis may result from uterine atony. However, the time from uterine inversion to the development of necrosis is unknown. A previous study in the uteri of cynomolgus macaques showed that ischemia for 4 hours caused mild muscle degeneration and zonal degeneration. Periodical menstruation resumed in all animals with ischemia up to 4 hours, but animals with ischemia for 8 hours did not recover menstruation and 
had atrophic uteri [8]. In our case, uterine inversion persisted for up to 4 hours, and although it is necessary to consider the influence of balloon tamponade and uterine artery embolization, necrosis was observed in the uterine fundus and on the surface of the surrounding muscle layer. Four hours might be the critical time from the occurrence of uterine inversion to the probable development of necrosis, but this requires further study.

In our case, we first performed balloon tamponade and uterine artery embolization instead of hysterectomy due to the risk of perioperative hemorrhaging secondary to disseminated intravascular coagulation and the momentum of bleeding. Had we stabilized her hemodynamic condition before replacement of the inverted uterus or replaced the inverted uterus under laparotomy, we may have been able to perform hysterectomy promptly even if the bleeding increased.

\section{Conclusions}

In summary, acute uterine inversion generally needs prompt replacement of the inverted uterus. However, when uterine inversion with coagulopathy persists for more than 4 hours, clinicians should consider stabilizing the maternal hemodynamic condition before replacement of the inverted uterus or should consider a surgical approach without undue delay. To the best of our knowledge, this is the first case report on a novel management strategy of acute uterine inversion with coagulopathy that persisted for a significant period of time.

\section{Acknowledgements}

We thank Editage (www.editage.jp) for English-language editing.

\section{Authors' contributions}

DK conceived and wrote the first draft of the manuscript. SM, ST, KS, KY, MO FK, and TM critically reviewed and revised the manuscript. The authors read and approved the final manuscript.

\section{Funding}

Not applicable.

\section{Availability of data and materials}

Not applicable.

Ethics approval and consent to participate

Not applicable.

\section{Consent for publication}

Written informed consent was obtained from the patient for publication of this case report and any accompanying images. A copy of the written consent is available for review by the Editor-in-Chief of this journal.

\section{Competing interests}

The authors declare that they have no competing interests.

\section{Author details}

'Department of Obstetrics and Gynecology, Shiga University of Medical Science Hospital, Setatsukinowa-cho, Otsu, Shiga 520-2192, Japan.

2 Department of Diagnostic Pathology, Shiga University of Medical Science

Hospital, Setatsukinowa-cho, Otsu, Shiga 520-2192, Japan.
Received: 27 July 2020 Accepted: 10 September 2020

Published online: 08 October 2020

References

1. Witteveen T, van Stralen G, Zwart J, van Roosmalen J. Puerperal uterine inversion in the Netherlands: a nationwide cohort study. Acta Obstet Gynecol Scand. 2013;92:334-7.

2. Brokenshire J, Thomas J. Uterine inversion and postpartum hemorrhage Emerg Med Cases. 2016. https://emergencymedicinecases.com/uterineinversion/. Accessed 30 Sept 2019.

3. Sunjaya AP, Dewi AK. Total uterine inversion post partum: case report and management strategies. J Family Reprod Health. 2018;12:223-5.

4. Soleymani MH, Pilsniak A, Reginald PW. Recurrent uterine inversion: a novel treatment approach using SOS Bakri balloon. BJOG. 2009;116:999-1001.

5. Matsubara S. Uterine compression suture may be useful not only for hemostasis in postpartum hemorrhage but also for prophylaxis of acute recurrence of uterine inversion. Arch Gynecol Obstet. 2010;281:1081-2.

6. Guasch E, Gilsanz F. Massive obstetric hemorrhage: current approach to management. Med Int. 2016;40:298-310.

7. Collins PW, Lilley G, Bruynseels D, Laurent DB, Cannings-John R, Precious E, et al. Fibrin-based clot formation an early and rapidly available biomarker for progression of postpartum hemorrhage: a prospective cohort study. Blood. 2014;124:1727-36

8. Kisu I, Umene K, Adachi M, Emoto K, Nogami Y, Banno K, et al. Allowable warm ischemic time and morphological and biochemical changes in uterine ischemia/reperfusion injury in cynomolgus macaque: a basic study for uterus transplantation. Hum Reprod. 2017;32:2026-35.

\section{Publisher's Note}

Springer Nature remains neutral with regard to jurisdictional claims in published maps and institutional affiliations.
Ready to submit your research? Choose BMC and benefit from:

- fast, convenient online submission

- thorough peer review by experienced researchers in your field

- rapid publication on acceptance

- support for research data, including large and complex data types

- gold Open Access which fosters wider collaboration and increased citations

- maximum visibility for your research: over $100 \mathrm{M}$ website views per year

At BMC, research is always in progress.

Learn more biomedcentral.com/submissions 